\title{
Pemanfaatan Material Lokal Pasir Samboja Sebagai Campuran Beton Mutu Tinggi
}

\author{
Drs. Sunarno, M. Eng'), Totok Sulistyo, ST., MT ${ }^{2)}$, Karmila Achmad, ST.,MT ${ }^{3)}$, \\ ${ }^{1}$ Teknik Sipil, Politeknik Negeri Balikpapan \\ e-mail : sunarno@poltekba.ac.id, \\ ${ }^{2}$ Teknik Sipil, Politeknik Negeri Balikpapan \\ totok.sulistyo@poltekba.ac.id, \\ ${ }^{3}$ Teknik Sipil, Politeknik Negeri Balikpapan \\ milabpp@yahoo.com
}

\begin{abstract}
Balikpapan in East Kalimantan as the gate is a city that is currently growing rapidly. With the demands as the industrial city of many emerging major projects. And do not rule out the possibility in the future needed large projects using high strength concrete in Balikpapan

The purpose of this study was to obtain local materials that are generally used in the area of Balikpapan is Pasir Samboja as a new alternative that can be used as a high quality concrete for large projects in Balikpapan

This research used local material to form a High Strength Concrete. The material were: a). Samboja Sand, Kutai Kertanegara, East Kalimantan, whose the physical characteristic as follow: Specific Gravity = 2,573 $\mathrm{gr} / \mathrm{cm}^{3}$, Dry-Surface Density $=2,622 \mathrm{gr} / \mathrm{cm}^{3}$, Unit-Weight no compacted = 1,475 $\mathrm{gr} / \mathrm{cm}^{3}$, Absorption $=1,895 \%$, Clay Lump = 2,20\% (in accordance with SNI S-04-1989-F) and Fineness Modulus = 1,544 ; b) Gravel from Palu with the physical characteristic i.e: Specific Gravity $=2,658 \mathrm{gr} / \mathrm{cm}^{3}$, Dry-Surface Density $=2,675 \mathrm{gr} / \mathrm{cm}^{3}$, Unit-Weight no compacted $=1,504 \mathrm{gr} / \mathrm{cm}^{3}$, Absorption $=0,675 \%$, and Fineness Modulus Gravel=6.903. Los Angeles test result was the broken part took $31.07 \%$ that smaller than $40 \%$ meaning it can be used for concrete class II (K-125 to K-225) according to SNI 03-6861.1-2002. The concrete strength with the additional of Sikament NN 1\%, 2\%, 2,5\% and 3\% are 19,093 MPa, 21,090 MPa, 26,585MPa and 24,123 MPa. The conclusion of this research are concrete strength increased with the addition of Sikament NN $2.5 \%$ and decreased with the addition of Sikament NN 3\%.

Keywords: Aggregate, Samboja Sand, High Strength Concrete
\end{abstract}

\begin{abstract}
Abstrak
Balikpapan sebagai pintu gerbang Kalimantan Timur merupakan kota yang saat ini sedang tumbuh pesat. Dengan tuntutan sebagai kota industri maka banyak bermunculan proyek-proyek besar. Dan tidak menutup kemungkinan di masa yang akan datang dibutuhkan proyek-proyek besar dengan menggunakan beton mutu tinggi di Balikpapan

Tujuan penelitian ini adalah untuk mendapatkan material lokal yang secara umum digunakan di wilayah Balikpapan yaitu Pasir Samboja sebagai alternatif baru yang dapat digunakan sebagai beton mutu tinggi untuk proyek-proyek besar di Balikpapan

Dalam penelitian ini Karakteristik fisik material lokal pembentuk beton mutu tinggi meliputi: Pasir Samboja, Kutai Kertanegara, Kalimantan Timur adalah: Berat jenis 2,573 gr/ $\mathrm{cm}^{3}$, berat jenis kering muka (SSD) sebesar 2,622 $\mathrm{gr} / \mathrm{cm}^{3}$, berat satuan tanpa pemadatan 1,475 $\mathrm{gr} / \mathrm{cm}^{3}$, daya serap air sebesar 1,895\%. Kandungan lumpur sebesar 2,20 \% sehingga memenuhi syarat SK SNI S-04-1989F.Gradasi pasir dengan modulus halus butir $(\mathrm{mhb})$ 1,544. Kerikil asal Palu meliputi: Berat jenis 2,658 $\mathrm{gr} / \mathrm{cm}^{3}$, berat jenis kering muka (SSD) sebesar 2,675 $\mathrm{gr} / \mathrm{cm}^{3}$, daya serap air sebesar 0,675\% dan berat satuan tanpa pemadatan 1,504 $\mathrm{gr} / \mathrm{cm}^{3}$. Hasil uji Los Angeles bagian yang hancur 31,07 \% lebih kecil dari 40\% yang disyaratkan SNI 03-6861.1-2002 dapat dipakai untuk beton kelas II (K-125 sampai K225). Modulus halus butir kerikil 6,903. Kuat tekan rata-rata beton meningkat pada penambahan Sikament NN 2,5\% namun kuat tekan mengalami penurunan pada penambahan Sikament NN 3\%, dengan rincian sebagai berikut : Beton dengan bahan tambah Sikament NN 1\% mempunyai kuat tekan rata-rata 19,093 MPa, untuk Sikament NN 2\% memiliki kuat tekan rata-rata 21,090 MPa, sedangkan untuk Sikament NN 2,5\% mempunyai kuat tekan rata-rata 26,585 MPa dan untuk Sikament NN 3\% mempunyai kuat tekan rata-rata 24,123 Mpa
\end{abstract}

Kata Kunci : Agregat, pasir Samboja, Beton Mutu Tinggi 


\section{Pendahuluan}

Balikpapan sebagai pintu gerbang Kalimantan Timur merupakan kota yang saat ini sedang tumbuh pesat. Dengan tuntutan sebagai kota industri maka banyak bermunculan proyek-proyek besar. Dan tidak menutup kemungkinan 5 tahun yang akan datang dibutuhkan proyek-proyek besar dengan menggunakan beton mutu tinggi di Balikpapan. Namun hal ini kurang didukung karena tingginya biaya yang harus dikeluarkan untuk sebuah proyek. Perlu diketahui saat ini semua material harus didatangkan dari luar daerah. Hal ini lah yang menuntut putra daerah di bidang akademisi untuk mencari suatu solusi material lokal yang dapat digunakan sesuai dengan kebutuhan industri konstruksi saat ini.

Salah satu material pembentuk beton adalah agregat halus. Dalam penelitian ini akan digunakan pasir Samboja. Pasir Samboja merupakan material lokal yang saat ini dominan dipakai sebagai mortar pasangan tembok dan plesteran karena butirannya yang halus. Umumnya pasir Samboja digunakan untuk beton non structural dan sebagai campuran pasir Palu. Penelitian pendahuluan berupa pemanfaatan pasir Samboja sebagai campuran beton normal telah dilakukan dan terbukti bahwa pasir Samboja memiliki kekuatan yang tinggi (Sunarno, 2008).

Adapun tujuan dari penelitian ini adalah Mendapatkan karakteristik fisik material lokal yang secara umum digunakan di wilayah Balikpapan yaitu pasir Samboja dan kerikil Palu

\section{Metode Penelitian}

$$
\text { Dalam melakukan penelitian }
$$

Pemanfaatan Material Lokal Pasir Samboja sebagai Campuran Beton Mutu Tinggi, tahapan yang akan dilakukan adalah sebagai berikut:
- Tahap Persiapan

Pada tahap ini dipersiapkan bahanbahan yang akan digunakan untuk membuat benda uji yaitu pasir, kerikil, semen dan air. Selain itu juga dipersiapkan alat-alat yang akan digunakan dalam pengujian bahan maupun untuk pembuatan dan pengujian benda uji.

\section{- Tahap Pemeriksaan Bahan}

Pemeriksaan bahan diperlukan untuk mengetahui sifat bahan yang dipakai untuk perancangan campuran adukan beton. Pemeriksaan bahan ini terdiri dari pemeriksaan pasir dan kerikil. Pemeriksaan pasir terdiri dari pemeriksaan kandungan lumpur dan zat organis, berat jenis, daya serap air, gradasi dan berat satuan, modulus halus butir (mhb). Pemeriksaan kerikil dilakukan terutama pada kondisi kerikil jenuh kering muka kecuali pada uji keausan pada kondisi kering tungku. Pemeriksaan kerikil terdiri dari pemeriksaan berat jenis, berat satuan, daya serap air, modulus halus butir (mhb) dan kekerasan.

\section{- Tahap perancangan adukan}

Tujuan utama mempelajari sifat-sifat bahan susun beton adalah untuk perencanaan campuran (mix design), yaitu pemilihan dari bahan-bahan beton yang memadai, serta menentukan proporsi masing-masing bahan untuk menghasilkan beton yang ekonomis dengan kualitas yang baik. Syarat-syarat beton keras ditentukan oleh jenis struktur dan teknik pengecoran (perletakan, pengangkutan dan pemadatan). Kedua hal ini menentukan komposisi dari campuran, dengan memperhatikan pengawasan di lapangan. Metode perencanaan campuran dalam penelitian ini sesuai dengan SNI 03-2834-1993.

- Tahap pengadukan, pencetakan dan perawatan

- Tahap pengujian 


\section{Hasil Pembahasan}

Tabel 1. Hasil Pengujian Pasir Samboja, Kutai Kertanegara, Kalimantan Timur

\begin{tabular}{|c|l|c|c|l|l|}
\hline No & Tinjauan & Hasil & Prasayarat & \multicolumn{1}{|c|}{ Code } & Kesimpulan \\
\hline A & Berat Jenis & 2,573 & $2,5-2,7$. & $\begin{array}{l}\text { SNI 03-1970- } \\
1990\end{array}$ & $\begin{array}{l}\text { Memenuhi } \\
\text { syarat }\end{array}$ \\
\hline $\begin{array}{l}\text { Berat Jenis } \\
\text { SSD }\end{array}$ & 2,622 & $2,5-2,7$ & $\begin{array}{l}\text { SNI 03-1970- } \\
1990\end{array}$ & $\begin{array}{l}\text { Memenuhi } \\
\text { syarat }\end{array}$ \\
\hline B & $\begin{array}{l}\text { Berat } \\
\text { Satuan }\end{array}$ & $\begin{array}{c}1,475 \\
\text { gr/cm3 }\end{array}$ & $1,50-1,80$ & $\begin{array}{l}\text { SNI 03-4804- } \\
1998\end{array}$ & $\begin{array}{l}\text { Tidak } \\
\text { memenuhi } \\
\text { syarat }\end{array}$ \\
\hline C & $\begin{array}{l}\text { Daya serap } \\
\text { air }\end{array}$ & $1.895 \%$ & $0,5 \%-1 \%$ & $\begin{array}{l}\text { SNI 03-1970- } \\
1990\end{array}$ & $\begin{array}{l}\text { Tidak } \\
\text { memenuhi } \\
\text { syarat }\end{array}$ \\
\hline D & $\begin{array}{l}\text { Kandungan } \\
\text { Lumpur }\end{array}$ & $2,20 \%$ & $5 \%$ & PUBI-1992 & $\begin{array}{l}\text { Memenuhi } \\
\text { syarat }\end{array}$ \\
\hline E & $\begin{array}{l}\text { Kandungan } \\
\text { zat organik }\end{array}$ & $\begin{array}{c}\text { Warna lebih } \\
\text { muda dari } \\
\text { warna } \\
\text { standar }\end{array}$ & $\begin{array}{c}\text { Warna lebih } \\
\text { muda dari } \\
\text { warna standar }\end{array}$ & SII.0052 -80 & $\begin{array}{l}\text { Memenuhi } \\
\text { syarat }\end{array}$ \\
\hline F & Gradasi & Mhb 1,544 & Mhb 1,5-3,8 & $\begin{array}{l}\text { SNI 03-1968- } \\
1990\end{array}$ & $\begin{array}{l}\text { Tidak } \\
\text { memenuhi } \\
\text { svarat }\end{array}$ \\
\hline
\end{tabular}

Berat jenis kering pasir sebesar 2,573 $\mathrm{gr} / \mathrm{cm}^{3}$. Berat jenis jenuh kering muka ( SSD ) sebesar 2,622. Berdasarkan berat jenisnya pasir Samboja memenuhi syarat agregat normal yang berat jenisnya antara 2,5 sampai 2,7.

Berat satuan agregat halus yang diperoleh $1,475 \mathrm{gr} / \mathrm{cm}^{3}$.Menurut Tjokrodimuljo (2007). dalam praktek umumnya nilai berat satuan untuk agregat normal adalah 1,50 - 1,80. Dengan demikian pasir Samboja tidak termasuk dalam agregat normal. Meskipun demikian agregat halus tetap diperlakukan sebagai agregat normal, dengan alasan salah satu tujuan penelitian ini adalah untuk mengetahui seberapa besar nilai kuat tekan beton yang akan dihasilkan.

Daya serap air sebesar $1.895 \%$. Menurut Shetty (1997), pada umumnya daya serap air agregat kasar berkisar $0,5 \%$ sampai $1 \%$ dengan demikian pasir Samboja mempunyai penyerapan cukup tinggi, sehingga tidak memenuhi syarat

Kandungan lumpur agregat halus sebesar $2.20 \%$; dengan demikian agregat halus tidak perlu dicuci karena kandungan lumpur tidak lebih dari $5 \%$ sehingga memenuhi syarat menurut PUBI-1982
Tabel 2. Hasil Pengujian Kerkil asal Palu

\begin{tabular}{|c|l|c|c|l|l|}
\hline No & Tinjauan & Hasil & Prasayarat & \multicolumn{1}{|c|}{ Code } & Kesimpulan \\
\hline A & Berat Jenis & 2,658 & $2,5-2,7$. & $\begin{array}{l}\text { SNI 03-1970- } \\
1990\end{array}$ & $\begin{array}{l}\text { Memenuhi } \\
\text { syarat }\end{array}$ \\
\hline & $\begin{array}{l}\text { Berat Jenis } \\
\text { SSD }\end{array}$ & 2,675 & $2,5-2,7$ & $\begin{array}{l}\text { SNI 03-1970- } \\
1990\end{array}$ & $\begin{array}{l}\text { Memenuhi } \\
\text { syarat }\end{array}$ \\
\hline B & $\begin{array}{l}\text { Berat } \\
\text { Satuan }\end{array}$ & $\begin{array}{l}1,504 \\
\text { gr/cm3 }\end{array}$ & $1,50-1,80$ & $\begin{array}{l}\text { SNI 03-4804- } \\
1998\end{array}$ & $\begin{array}{l}\text { Memenuhi } \\
\text { syarat }\end{array}$ \\
\hline C & $\begin{array}{l}\text { Daya serap } \\
\text { air }\end{array}$ & $0,645 \%$ & $0,5 \%-1 \%$ & $\begin{array}{l}\text { SNI 03-1970- } \\
1990\end{array}$ & $\begin{array}{l}\text { Tidak } \\
\text { memenuhi } \\
\text { syarat }\end{array}$ \\
\hline D & $\begin{array}{l}\text { Kandungan } \\
\text { Lumpur }\end{array}$ & $0,56 \%$ & $5 \%$ & PUBI-1992 & - \\
\hline E & $\begin{array}{l}\text { Ketahanan } \\
\text { aus }\end{array}$ & $31,07 \%$ & $50 \%$ & $\begin{array}{l}\text { SNI 03-2417- } \\
1990\end{array}$ & $\begin{array}{l}\text { Memenuhi } \\
\text { syarat }\end{array}$ \\
\hline F & Gradasi & Mhb 6,903 & Mhb 6,5-7,10 & $\begin{array}{l}\text { SNI 03-1968- } \\
1990\end{array}$ & $\begin{array}{l}\text { Memenuhi } \\
\text { syarat }\end{array}$ \\
\hline
\end{tabular}

Berat jenis agregat kasar yang diuji ratarata 2,658. Berat jenis jenuh kering muka (SSD) rata-rata sebesar 2,675. Berdasarkan berat jenis kerikil asal Palu memenuhi syarat agregat normal yang berat jenisnya antara 2,5 sampai 2,7.

Berat satuan agregat kasar yang diperoleh $1,504 \mathrm{gr} / \mathrm{cm}^{3}$. Menurut Tjokrodimuljo (2007). dalam praktek umumnya nilai berat satuan untuk agregat normal adalah 1,50 - 1,80. Dengan demikian kerikil asal Palu termasuk dalam agregat normal.

Daya serap air Kerikil Palu sebesar 0.645\%. Menurut Shetty (1997), pada umumnya daya serap air agregat kasar berkisar $0,5 \%$ sampai $1 \%$ dengan demikian kerikil asal Palu mempunyai penyerapan cukup tinggi

Kerikil dalam penelitian ini tidak dilakukan pemeriksaan kandungan lumpur karena sebelumnya sudah dilakukan pencucian terlebih dahulu dengan air bersih sehingga dianggap tidak mengandung lumpur.

Dari pengujian kekerasan agregat kasar dengan menggunakan mesin Los Angeles didapat bagian yang hancur sebesar 31.07 $\%$. Menurut SNI 03-6861-2002, maka beton yang dibuat dengan menggunakan agregat kasar ini diperkirakan masuk beton kelas III dengan mutu K-225 (f 'c $=20 \mathrm{MPa}$ ). 
Dengan demikian kerikil asal Palu mempunyai ketahanan aus yang baik karena terdiri dari bahan butiran yang kuat.

Tabel 3. Kebutuhan bahan tiap $1 \mathrm{~m}^{3}$ beton

\begin{tabular}{|c|c|c|c|c|c|c|c|c|c|c|}
\hline \multirow{3}{*}{ Kode Benda Uji } & \multirow{3}{*}{ Fas } & \multicolumn{9}{|c|}{ Hasil Penelitian } \\
\hline & & \multirow{2}{*}{$\begin{array}{l}\text { Jumlah } \\
\text { Semen } \\
\left(\mathrm{kg} / \mathrm{m}^{3}\right)\end{array}$} & \multirow{2}{*}{$\begin{array}{c}\text { Air } \\
\text { (liter) }\end{array}$} & \multicolumn{2}{|c|}{ Sikament NN } & \multirow{2}{*}{$\begin{array}{l}\text { Berat } \\
\text { Beton } \\
\left(\mathrm{kg} / \mathrm{m}^{3}\right)\end{array}$} & \multirow{2}{*}{$\begin{array}{l}\text { Perbandingan } \\
\text { Agr:Halus : } \\
\text { Kasar }\end{array}$} & \multirow{2}{*}{$\begin{array}{c}\text { Berat } \\
\text { Agregat } \\
\left(\mathrm{kg}^{3} \mathrm{~m}^{3}\right)\end{array}$} & \multirow{2}{*}{$\begin{array}{l}\text { Berat } \\
\text { Agregat } \\
\text { Kalus } \\
\left(\mathrm{kg}^{3} \mathrm{~m}^{3}\right)\end{array}$} & \multirow{2}{*}{$\begin{array}{c}\text { Berat } \\
\text { Agrega } \\
\text { Kasar } \\
\left(\mathrm{kg} / \mathrm{m}^{3}\right)\end{array}$} \\
\hline & & & & $\begin{array}{c}\% \times \text { Berat } \\
\text { Semen }\end{array}$ & Jumlah(ml) & & & & & \\
\hline $\mathrm{A} 1=\mathrm{B} 1=\mathrm{Cl}=\mathrm{D} 1$ & 0,3 & 700,00 & 210 & $1 \%$ & 7,00 & 2375 & $38: 62$ & 1465,00 & 556,7 & 908,30 \\
\hline $\mathrm{A} 2=\mathrm{B} 2=\mathrm{C} 2=\mathrm{D} 2$ & 0,3 & 700,00 & 210 & $2 \%$ & 14,00 & 2375 & $38: 62$ & 1465,00 & 556,7 & 908,30 \\
\hline $\mathrm{A} 3=\mathrm{B} 3=\mathrm{C} 3=\mathrm{D} 3$ & 0,3 & 700,00 & 210 & $2,50 \%$ & 17,50 & 2375 & $38: 62$ & 1465,00 & 556,7 & 908,30 \\
\hline $\mathrm{A} 4=\mathrm{B} 4=\mathrm{CA}=\mathrm{D} 4$ & 0,3 & 700,00 & 210 & $3 \%$ & 21,00 & 2375 & $38: 62$ & 1465,00 & 556,7 & 908,30 \\
\hline
\end{tabular}

Tabel 4. Kuat Tekan Beton

\begin{tabular}{|c|c|c|c|c|c|c|}
\hline \multirow{2}{*}{$\begin{array}{c}\text { Kode } \\
\text { Benda } \\
\text { Uji }\end{array}$} & \multirow{2}{*}{$\begin{array}{c}\text { Nomer } \\
\text { Benda } \\
\text { Uji }\end{array}$} & \multirow{2}{*}{ Fas } & \multirow{2}{*}{ Sikament } & \multicolumn{3}{|c|}{ Kuat Tekan (Mpa) } \\
\hline & & & & $\underset{\text { hari }}{\operatorname{Umur} 3}$ & $\begin{array}{c}\text { Umur } 7 \\
\text { hari }\end{array}$ & $\begin{array}{c}\text { Umur } 28 \\
\text { hari }\end{array}$ \\
\hline \multirow{4}{*}{ A } & 1 & \multirow{4}{*}{0,3} & \multirow{4}{*}{$1 \%$} & 15270 & 14756 & 25820 \\
\hline & & & & & & \\
\hline & 2 & & & 16,139 & 11,067 & 32,462 \\
\hline & 3 & & & 16,907 & 10,540 & 28,773 \\
\hline $\begin{array}{l}\text { Rata- } \\
\text { rata }\end{array}$ & & & & 16,139 & 12,121 & 29,019 \\
\hline \multirow{3}{*}{ B } & 1 & \multirow{3}{*}{0,3} & \multirow{3}{*}{$2 \%$} & 16,139 & 26,349 & 19,182 \\
\hline & 2 & & & 16,907 & 28,457 & 17,707 \\
\hline & 3 & & & 16,907 & 32,673 & 15,493 \\
\hline $\begin{array}{c}\text { Rata- } \\
\text { rata }\end{array}$ & & & & 16,651 & 29,160 & 17,461 \\
\hline \multirow{3}{*}{$\mathrm{C}$} & 1 & \multirow{3}{*}{0,3} & \multirow{3}{*}{$2,50 \%$} & 23,824 & 30,565 & 22,133 \\
\hline & 2 & & & 23,056 & 29,511 & 26,560 \\
\hline & 3 & & & 24,593 & 29,511 & 29,511 \\
\hline $\begin{array}{l}\text { Rata- } \\
\text { rata }\end{array}$ & & & & 23,824 & 29,862 & 26,068 \\
\hline \multirow{3}{*}{ D } & 1 & \multirow{3}{*}{0,4} & \multirow{3}{*}{$3 \%$} & 25,950 & 25,073 & 21,515 \\
\hline & 2 & & & 27,129 & 24,264 & 19,250 \\
\hline & 3 & & & 28,309 & 27,500 & 18,117 \\
\hline $\begin{array}{l}\text { Rata- } \\
\text { rata }\end{array}$ & & & & 27,129 & 25,612 & 19,627 \\
\hline
\end{tabular}

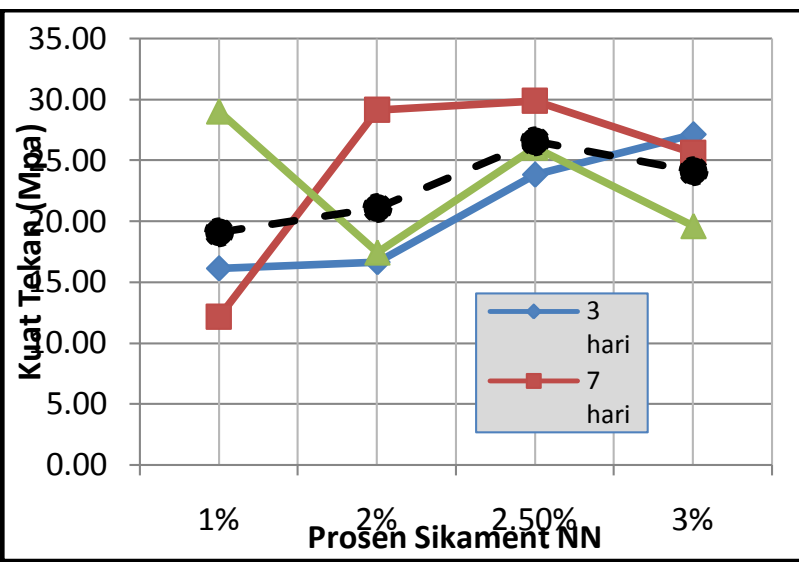

Gambar 1. Grafik kuat Tekan beton hasil penelitian
Kuat tekan rata-rata beton meningkat pada penambahan Sikament NN 2,5\% namun kuat tekan mengalami penurunan pada penambahan Sikament NN 3\%, dengan rincian sebagai berikut : Beton dengan bahan tambah Sikament NN $1 \%$ mempunyai kuat tekan rata-rata 19,093 $\mathrm{MPa}$, untuk Sikament NN 2\% memiliki kuat tekan rata-rata 21,090 $\mathrm{MPa}$, sedangkan untuk Sikament NN 2,5\% mempunyai kuat tekan rata-rata 26,585 $\mathrm{MPa}$ dan untuk Sikament NN 3\% mempunyai kuat tekan rata-rata 24,123 Mpa

\section{Kesimpulan}

Kuat tekan rata-rata beton meningkat pada penambahan Sikament NN 2,5\% namun kuat tekan mengalami penurunan pada penambahan Sikament NN 3\%, dengan rincian sebagai berikut :

Beton dengan bahan tambah Sikament NN $1 \%$ mempunyai kuat tekan rata-rata 19,093 MPa, untuk Sikament NN 2\% memiliki kuat tekan rata-rata 21,090 MPa, sedangkan untuk Sikament NN 2,5\% mempunyai kuat tekan rata-rata 26,585 MPa dan untuk Sikament NN 3\% mempunyai kuat tekan rata-rata 24,123 Mpa

\section{Ucapan Terimakasih}

Terima kasih penulis sampaikan kepada Direktur, Kepala Pusat Penelitian dan Pengabdian Masyarakat (P3M) Politeknik Negeri Balikpapan yang telah membantu kelancaran Penelitian ini.

\section{Daftar Pustaka}

http://pramudiyanto.wordpress.com/2008/ 08/06/beton-mutu-tinggi/

http://www.scribd.com/doc/38419085/FX$\underline{\text { Supartono }}$ 
NSPM Kimpraswil , 2002, Metode,Spesifikasi dan Tata Cara Bagian 2, Departemen Permukiman dan Prasarana Wilayah Badan Penelitian dan Pengembangan, Jakarta.

NSPM Kimpraswil, 2002, Metode,Spesifikasi dan Tata Cara Bagian 3, Departemen Permukiman dan Prasarana Wilayah Badan Penelitian dan Pengembangan, Jakarta.

Nugraha, Paul, 2007, Teknologi Beton ,Penerbit Andi, Yogyakarta

SNI 03-1972-1990, Metode Pengujian Slump Beton.
SNI 03-1974-1990, Metode Pengujian Kuat Tekan Beton

SNI 03-1968-1990, Metode Pengujian Tentang Analisa Saringan Agregat Halus dan Kasar

Tjokrodimulyo, K., 2007, Teknologi Beton, Biro Penerbit Teknik Sipil Universitas Gadjah Mada, Yogyakarta

Sunarno, 2008, Pemanfaatan Pasir Samboja dan Kerikil asal Palu sebagai Bahan Pembuatan Beton Normal, Tesis, Sekolah Pasca Sarjana Universitas Gadjah Mada, Yogyakarta. 